\title{
Intrinsic and Extrinsic Factors Predicting the Cumulative Outcome of IVF / ICSI Treatment
}

\author{
Gowramma G S, Shantharam Nayak, Nagaraj Cholli
}

\begin{abstract}
Infertility rates in India becoming increased in last decade principally due to the urbanization conditions and the lifestyle habits. It is giving alarm by continuously reporting the progress in incident cases of infertility amongst the young Indian adults of both male and female population. Among the various Assisted Reproductive Technologies (ART) available today in the treatment of infertility, In Vitro Fertilization (IVF) is found to be the most applicable treatment method of choice. This involves the administration of different hormones and drugs to treat infertility. In the present scenario technically IVF treatment process is tedious, laborious, high cost and most importantly success rates reported to be very low (20-30\%). The prediction of IVF success rates is becoming an important scientific knowledge and practice, which helps both the doctor and the candidate couple to know about the conditions hence to take the right decision. The accurate prediction of the IVF success rate is really a challenging task in obstetrics and gynecology medicine. The success rates of the IVF depends on the various factors such as Intrinsic factors i.e, Genetic predisposition, Age, Body mass Index, Hormonal balance, Embryo viability, Sperm quality, Endometriosis and overall patient's response level of the candidate couple and the Extrinsic factors such as Medical equipment technology, Treatment methods, Personal experiences of clinicians and embryologists, Process time, Stress due to the lifestyle etc.
\end{abstract}

Keywords:Success rates prediction, Data analytics, Intrinsic factors, Extrinsic factors.

\section{INTRODUCTION}

In humans, a condition of infertility is refer to as failure to become conceive or carries a pregnancy naturally to full term. World Health Organization defined Infertility condition of the humans beings as 'a kind of reproductive system disorder or failure, which reduces or cause a total failure to achieve the

state of condition known as pregnancy even after 1 year of continuous, regular, on fertile days with unprotected intercourse without any pregnancy control measures and with no other significant clinical cause such as breast feeding or postpartum amenorrhea. The state of infertility can be calcified in to two different categories such as Primary infertility and Secondary infertility. Primary infertility refers to the condition of a total failure of the reproductive system to become pregnant and in this case couple's never have a possibility of giving birth to child with natural or normal pregnancy.

Revised Manuscript Received on December 22, 2019

Mrs. Gowramma G.S, Associate Professor, Department of Information Science \& Engineering, Don Bosco Institute of Technology, Bengaluru, Karnataka, India.

Dr. Shantharam Nayak, Professor, Department of Information Science \& Engineering, R. V. College of Engineering, Bengaluru, Karnataka, India.

Dr. Nagaraj G Cholli, Computer Science \& Engineering, Visvesvaraya Technological University Belagavi, Karnataka, India.

Secondary infertility explains the failure of a female to become pregnant after giving successful live birth to child in first pregnancy in a period of 12 months' time interval [1]. Infertility in humans beings is induced and promoted by variety of causes such as Immune infertility found in 10 $30 \%$ cause of infertile couples id developed due to the action of Antisperm antibodies (ASA) on sperm cells and cause infertility, Sexually transmitted infections caused by the infectious microorganisms known as Chlamydia trachomatis and Neisseria gonorrhoeae found to have a negative effect on fertility and promotes infertility, genetic condition known as a Robertsonian translocation explained as kind of genetic mutation developed due to the change in the position of chromosomal portions of the either partner's may cause frequent impulsive abortions or absolute infertility. The affected male population display more rigorous forms of infertility conditions such as lack of sperm in ejaculation (azoospermia) and low sperm count(severe oligozoospermia); other well-known factors such as DNA damage and the inappropriate state of hormonal cycle and the balance reduces the chance of fertility in female population [2].

As per the WHO's report it is indicated that the spontaneous infertility may occur due to the influence of various medical malfunction conditions and cause infertility in $10 \%$ of the world population. According to the survey estimates report conducted on the causes of infertility published in the year 1997 , close to $5 \%$ of the world population considering among all the heterosexual couples were suffered with the infertility due to clinically unexplained and un resolved problems. Approximately 12 to $28 \%$ of the couples were found to be incident to the infertility condition with no significant medial changes and the predispositions [3]. Infertility in the male population was found be lesser compare to the other conditions and was reported in $20-30 \%$ of Infertility cases. Female infertility was little predominant in comparison with that of male infertility and contributes in $20-35 \%$ of the total infertility. Most sever infertility was found to be combined infertility occurs due to the combined problems both the sexual parts and contributes 25-40\% causes of the world infertility [4]. Deficiencies in semen structure, quality motility and total count were the most frequent causes of the male infertility, total absent or abnormal menstruation cycle manifest with the ovulation abnormalities are the major causatives in promoting female infertility. No significant reason was found in the 10-20\% cases of infertility [5][6].

Different treatment method are available to cure infertility conditions, type and method of treatment procedure applied is significantly depends up on the root cause of the infertility. 
Different drugs prescribed in the treatment of infertility both male and female includes Drug analogues of Gonadotropin releasing hormone $(\mathrm{GnRH})$-antagonize the action of the hormone, Aromatase inhibitors-Inhibits the role of enzyme aromatase, metformin clomiphene citrate and the different hormones applied as a hormonal therapy in the treatment of infertility were known to be Human menopausal Gonadotropin (hMG)-Hormone promotes the condition of menopause in women, Follicle stimulating hormone (FSH)enhance the formation of follicles in the women and Human chorionic gonadotropin (HCG) plays a significant role in the embryo development. Infertility treatments are classified as medical (or) complementary treatment methods and alternative treatments procedures. Among the medical treatments methods i.e Genetic counselling and Medical oriented Assisted Reproductive Technologies [ART]such as Intra Uterine Insemination (IUI)-release of sperm in uterine through injection, In vitro fertilization(IVF)-Fertilization of the ovule with the sperm applying microinjection carried out in laboratory condition, Intracytoplasmic sperm injection(ICSI), Zygote intrafallopian transfer (ZIFT), Gamete intrafallopian transfer (GIFT), donor egg, surrogacy and embryo transfer were the treatment methods available till today [7]. After the clinical confirmation of the infertility condition in the candidate of a couple, an appropriate ART treatment method is applied in order to make the woman conceive a carried out a successful pregnancy. ART provide childless couples a possibility to give birth to a baby child. The very first successful birth of healthier bay with IVF treatment was reported in the year 1998, since from this year many ART technologies i.e pre-implantation genetic diagnosis, embryo cryopreservation, Zygote intrafallopian transfer (ZIFT), Gamete intrafallopian transfer (GIFT), donor egg, surrogacy and embryo transfer gamete have been used as new treatment methods to achieve greater success in the treatment of infertility. Fertility treatment is carried out in three different phase's i.e the beginning phase of infertility treatment is IUI, less expensive but the success rate was reported to be less than $10 \%$ compared with the other ART treatment methods. After the IUI, IVF is considered to the most common procedure among the infertility treatments and considered to be the second phase treatment method after IUI procedure and possess increased success rate (20-39\%) compared with IUI. As per the present technology advance the third phase of the infertility treatment after the IVF is considered to be ICSI. Women aged less 35 years were reported to have $29 \%$ of success rate with the ICSI procedure. Among the various ART applied in the treatment of infertility IVF is considered to be the most common and successful treatment method applied today [8]. In the process of IVF, initially oocytes representing the female germ line cells are induced by the hormonal therapy and the generated matured oocytes were selected based on their quality and fertilization ability for the insemination step using sperm under Invitro (Laboratory) conditions. The embryos developed after the successful fertilization step are closely observed for about under 48-72 hrs under Invitro conditions. Further the embryos with controlled growth rates are identified and implanted in to the mother's womb at either cleavage stage of developing embryo (day 2-3) or after day 5-6 days aged embryo representing the at blastocyst stage. As per the nationwide survey IVF success rates were reported to be

close to $30 \%$ across hospitals and infertility centers of the country India [9].

Assessing the genetic and other health fitness of the candidate couple to predict the accurate success rates and withdrawn the conclusive suggestions based on the predictions will help to take decision on the IVF procedure whether to undergo or not is the most critical, challenging and important step which principally decides the success of the IVF procedure. So it is advised to estimate the success rate of the candidate couple by assessing the various intrinsic and the extrinsic factors such as Intrinsic factors i.e, Genetic predisposition, Age, Body mass Index, Hormonal balance, Embryo viability, Sperm quality, Endometriosis and overall patient's response level of the candidate couple and the Extrinsic factors such as Medical equipment technology, Treatment methods, Personal experiences of clinicians and embryologists, Process time, Stress due to the lifestyle etc... influencing the success of individual's IVF treatment cycles. If the success rate predicted was found to be low then the candidate's couple can take a conclusive decision such as not to go with the IVF cycle. In present scenario in generally doctors are withdrawing the suggestions principally based on their past experiences with the IVF procedure, this may not be accurate method and reduce the success rates. Easy availability and extensive utilization of the Internet in modern world gives scientific information to infertile couples and helps in educating them and provides increased attentiveness of the various treatment options along with their success rates. But the question is the reliability of the available information on the web, as most of the information was not an outcome of the validated accessed methods. Couples identified with infertility conditions desire to be acquainted with their probability of giving birth to child when choosing the right treatment options, selected based on their health and the clinical information [9].

\section{DATA MINING \& HEALTH CARE APPLICATIONS}

The rationale of data mining procedures is to dig out valuable information representing the information retrieved from the bulk databases or data warehouses. Data mining approaches are applied in find research solution and as well as for the in the business related commercial purpose. Data mining is the noteworthy procedure of recognizing useful, new, accurate and more importantly understandable patterns of information hiding in the raw data [Table 1].

\begin{tabular}{|c|c|c|c|c|c|}
\hline $\begin{array}{c}\text { Type of } \\
\text { disease }\end{array}$ & $\begin{array}{c}\text { Data } \\
\text { Mining } \\
\text { tool }\end{array}$ & Technique & $\begin{array}{c}\text { Algorit } \\
\text { hm }\end{array}$ & $\begin{array}{c}\text { Traditio } \\
\text { nal } \\
\text { Method }\end{array}$ & $\begin{array}{c}\text { Accuracy } \\
\text { Level (\%) } \\
\text { from DM } \\
\text { application }\end{array}$ \\
\hline $\begin{array}{c}\text { Heart } \\
\text { Disease }\end{array}$ & $\begin{array}{c}\text { ODND, } \\
\text { NCC2 }\end{array}$ & $\begin{array}{c}\text { Classificati } \\
\text { on }\end{array}$ & Naive & $\begin{array}{c}\text { Probabili } \\
\text { ty }\end{array}$ & 60.0 \\
\hline Cancer & WEKA & $\begin{array}{c}\text { Classificati } \\
\text { on }\end{array}$ & $\begin{array}{c}\text { Rules. } \\
\text { Decisio } \\
\text { n Table }\end{array}$ & -- & 97.77 \\
\hline $\begin{array}{c}\text { HIV/ } \\
\text { AIDS }\end{array}$ & $\begin{array}{c}\text { WEKA3. } \\
6\end{array}$ & $\begin{array}{c}\text { Classificati } \\
\text { on } \\
\text { Association } \\
\text { Rule } \\
\text { Mining }\end{array}$ & J48 & Statistics & 81.8 \\
\hline $\begin{array}{c}\text { Blood } \\
\text { Bank } \\
\text { Sector }\end{array}$ & WEKA & $\begin{array}{c}\text { Classificati } \\
\text { on }\end{array}$ & J48 & - & 89.9 \\
\hline
\end{tabular}




\begin{tabular}{|c|c|c|c|c|c|}
\hline $\begin{array}{c}\text { Brain } \\
\text { Cancer }\end{array}$ & $\begin{array}{c}\text { K-means } \\
\text { Clusterin } \\
\mathrm{g}\end{array}$ & Clustering & MAFIA & -- & 85.0 \\
\hline $\begin{array}{c}\text { Tubercul } \\
\text { osis }\end{array}$ & WEKA & $\begin{array}{c}\text { Naïve } \\
\text { Bayes } \\
\text { Classifier }\end{array}$ & KNN & $\begin{array}{c}\text { Probabili } \\
\text { ty, } \\
\text { Statistics }\end{array}$ & 78.0 \\
\hline $\begin{array}{c}\text { Diabetes } \\
\text { Mellitus }\end{array}$ & ANN & $\begin{array}{c}\text { Classificati } \\
\text { on }\end{array}$ & $\begin{array}{c}\text { C4.5 } \\
\text { algorith } \\
\text { m }\end{array}$ & $\begin{array}{c}\text { Neural } \\
\text { Network }\end{array}$ & $82 . .6$ \\
\hline $\begin{array}{c}\text { Kidney } \\
\text { dialysis }\end{array}$ & RST & $\begin{array}{c}\text { Classificati } \\
\text { on }\end{array}$ & $\begin{array}{c}\text { Decisio } \\
\text { n } \\
\text { Making }\end{array}$ & Statistics & 75.97 \\
\hline Dengue & $\begin{array}{c}\text { SPSS } \\
\text { Model }\end{array}$ & -- & C5.0 & Statistics & 80.0 \\
\hline IVF & $\begin{array}{c}\text { ANN,RS } \\
\text { T }\end{array}$ & $\begin{array}{c}\text { Classificati } \\
\text { on }\end{array}$ & -- & -- & 91.0 \\
\hline $\begin{array}{c}\text { Hepatitis } \\
\text { C }\end{array}$ & SNP & $\begin{array}{c}\text { Information } \\
\text { Gain }\end{array}$ & $\begin{array}{c}\text { Decisio } \\
\text { n Rule }\end{array}$ & -- & 73.20 \\
\hline
\end{tabular}

Table 1. Data mining applications in healthcare [11]

With the advent in extensive use of databases representing the IVF related health care data and the unstable escalation in their volume to transform in to BIG data, imposing the various health care organizations to face the difficulty in maintaining the data and also converting them or mining them to retrieve useful information. The only solution to deal with this problem is the application of various data mining algorithm to first convert Big data in to the structured form of data sets representing the multiple factors of the IVF procedure and further mine them to retrieve meaningful information to make suggestive conclusions.

BIG data analytics applied in the mining of IVF related data sets represents a various technical approaches of data assessment techniques i.e clustering methods, summarization methods of Big data, classification methods of raw data, finding dependency networks to validate the data sets, to analyzing changes happened in the raw data during the submission and the mining process, and detecting anomalies present with the raw data before classifying them to data sets, and computational algorithms, such as Logistic regression models, Case-Based Reasoning System (CBR), Decision Trees (DT), Naive Bayes classifiers, Artificial Neural Networks (ANN), and Hybrid methods with improved prediction capabilities to asses and validate the IVF data to retrieve the success prediction rates of the IVF procedure to help in making decisions. The present assessment of data mining applications is the outcome of influence from the various scientific and engineering domains, including various health care related databases, IVF data retrieval systems, statistics approaches, designed algorithms, bio simulation and machine learning tools. Healthcare industry nowadays generates bulky amounts of compound data representing the patients information, various hospital resources, different disease diagnosis results, numerous electronic patient records, the operation protocols and the calibration information to maintain Good Laboratory practices (GLP) as per USFDA, related information of the medical devices, instruments and the various laboratory conditions.

Health care related BIG data is an important resource of information and need to be analyzed thoroughly for the retrieval of knowledge based prior information of the IVF process that enhances the support strategies related to the treatment decision making and hence the saving the cost of the IVF cycle. Data mining applications applied in assessing the healthcare related BIG data shall be grouped into broad different categories such as treatment effectiveness, healthcare management, customer relationship management, fraud and abuse determination, medical device industry. Pharmaceutical industry, hospital management and system biology [11].

\section{FACTORS AFFECTING THE IVF SUCCESS RATES}

Many researchers reported about the positive influencing factors of the IVF procedure, but there is a profound lacunae found on the factors cause the failure of the IVF, both the positive and the negative factors are equally essential in predicting the accurate success rate of the IVF procedures. Bhattacharya et al, [12] studied varies factors associated with the failure of IVF treatment procedure by influencing the promotion of the each stage of the IVF procedure. Study collected a national wide seven years data related to the $1,21,744$ women undergone fresh IVF and ICSI cycles belong to the country United Kingdom from the unspecified data sources between the years 2000-2007 to identify the factors causing the failure of live birth and reduces the chance of becoming pregnant. Study applied a multivariable model approach to find the influence of neglected factors such as increase in age and absence of previous pregnancy of the candidate women, identification of tubal or male aspect infertility and time period of infertility for both men and women on the success rates of the IVF treatment process. Study reported that increase in age of the female candidate was found to possess significant percent of negative impact on the success of the IVF procedure and cause the high present failure of the Live birth, time period of infertility is also found to possess with negative outcomes of all the stages of the IVF cycle and cause the failure of the pregnancy and the live birth at very high rates. Male factor infertility was found to have least impact on the women undergoing ICSI procedure

Valerie et al, [13] compared gonadotropin therapy applied in the process of IVF, between the clinical trial information representing the databases of US trails with that of European trails in order to identify the factors promoting the IVF pregnancy rates and further to classify them as Intrinsic (Factors within the candidate) and extrinsic (Factors of the Environment, time, food habits, life style etc..). Study analyzed clinical trials data representing a total of 1297 women undergoing IVF treatment applying a multiple regression data mining approach. Study revealed that the pregnancy rates were found to be much higher with the US trails (43.3\%) compared with Europe trails (29.7\%). The percentage variation in the success rates were not able to explained by the factors studied such as number of embryos transferred, female age Table 2. Study concluded that the dosage (300 versus $225 \mathrm{IU}$ ), time period of the gonadotropin hormones therapy, endometrial baseline thickness in $\mathrm{mm}$ were reported to play a significant role in the success of IVF treatment. Other factors available in the national datasets which were not taken in the study may also contribute to the difference in pregnancy rates. 


\section{RESULT}

Table 2: Data representing the various factors influence the IVF success rates [13]

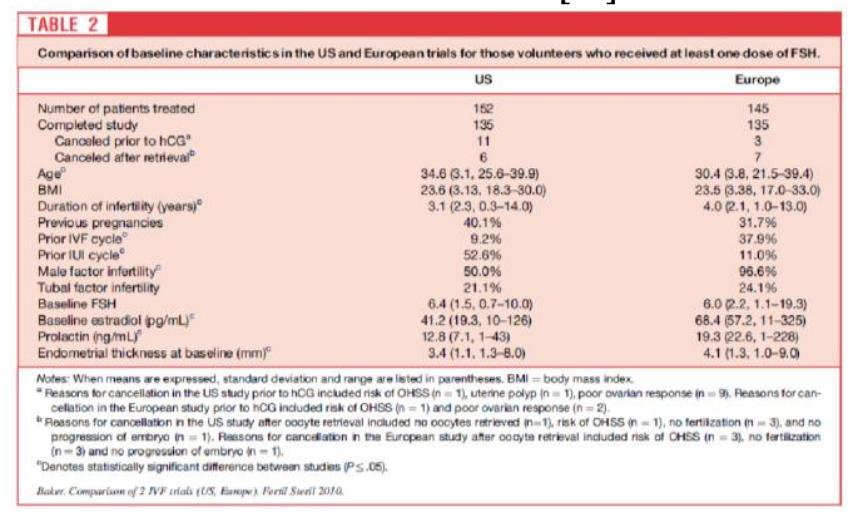

Veleva,[14] reported that the IVF success rates were influenced by the two different set of factors classified based on their origin such as Intrinsic and Extrinsic factors. Intrinsic factors are highly important and found to possess much higher level influence on the IVF success rates and were known as Genetic predisposition, Morphological Developmental Genetics, Female age, Body mass Index, Hormonal balance, Low ovarian response, Oocyte quality, Sperm quality, Endometrial receptivity, Metabolism, Overweight, obese, insulin resistantancy, Underweight women and overall patient's response level of the candidate couple and the Extrinsic factors such as Medical equipment technology, Treatment methods, Personal experiences of clinicians and embryologists, Process time, Stress due to the lifestyle Embryo quality, Quality of frozen-thawed embryos, Prognostic factors of LR Management of LRBMI as an outcome predictor of IVF/ICSI etc... are equally important in the prediction of the success rates of the IVF procedure of the candidate couple, but most of the clinicians are not considering the combitorial influence of both the intrinsic and the extrinsic factors. Factors studies alone may not able to support for the accurate prediction of IVF success rates because most of the factors denoted in intrinsic and the extrinsic were interdependent on each other so it is must that both intrinsic and the extrinsic factors in combination will certainly supports in estimating more accurate success rates of the IVF procedure which intern helpful to be the clinician and the candidate couple to take right decision.

\section{CONCLUSION}

In the modern world, pollution and the urban health care habits and the life style, are the two main factors promoting the incident rates of the infertility. Among the various ART technologies as of now the most reliable and most commonly applied treatment method to treat the infertility is IVF. The process of IVF is tedious, time consuming and high cost treatment methodology and the success of the procedure is influenced by the multi variables parameters such as Intrinsic factors i.e, Genetic predisposition, Age, Body mass Index, Hormonal balance, Embryo viability, Sperm quality, Endometriosis and overall patient's response level of the candidate couple and the Extrinsic factors such as Medical equipment technology, Treatment methods, Personal experiences of clinicians and embryologists, Process time, Stress due to the lifestyle etc.. Further work is to develop an automated decision support system to clinicians and the candidate couple by providing the more accurate success rates of IVF treatment which intern can be made available by assessing the influence of multiple factors of IVF process applying the various data mining algorithms and tools.

\section{REFERENCES}

1. WHO | Infertility". Who.int. 2013-03-19. Retrieved 2013-06-17.

2. Makar RS, Toth TL (2002). "The evaluation of infertility". Am J Clin Pathol. 117 (Suppl):S95-103. doi:10.1309/w8lj-k377-dhra cp0b PMID 14569805.

3. Himmel W, Ittner E, Kochen MM, Michelmann HW, Hinney B, Reuter $M$, Kallerhoff M, Ringert RH (1997). "Voluntary Childlessness and being Childfree". British Journal of General Practice. 47 (415): 111 8. PMC 1312893. PMID 9101672.

4. ART fact sheet (July 2014)". European Society of Human Reproduction and Embryology. Archived from the original on 4 March 2016.

5. Causes of infertility". National Health Service. Page last reviewed 15/07/2014.

6. Cooper TG, Noonan E, von Eckardstein S, Auger J, Baker HW, Behre HM, Haugen TB, Kruger T, Wang C, Mbizvo MT, Vogelsong KM (2010). "World Health Organization reference values for human semen characteristics". Hum. Reprod. Update. 16 (3): 231-45.

7. Edmund S. Sabanegh, Jr. (20 October 2010). Male Infertility: Problems and Solutions (https://books.google.com/books?id=YthJpK5clTMC \& pg=PA82). Springer Science \& Business Media. pp. 82-83. ISBN 978-1-60761193-6.

8. Ajay S. Patil. A Review of Soft Computing Used in Assisted Reproductive Techniques (ART). International Journal of Engineering Trends and Applications (IJETA) - Volume 2 Issue 3, May-June 2015. 88-93

9. H. Altay Güvenir · Gizem Misirli · Serdar Dilbaz • Ozlem Ozdegirmenci · Berfu Demir. Berna Dilbaz. Estimating the chance of success in IVF treatment using a ranking algorithm. Med Biol Eng Comput (2015) 53:911-920DOI 10.1007/s11517-015-1299-2.

10. Aslı Uyar Ozkaya. Assessing and enhancing machine learning methods in IVF process: predictive modelling of implantation and blastocyst development. Submitted to the Institute for Graduate Studies in Science and Engineering in partial fulfilment of the requirements for the degree of Doctor of Philosophy. Graduate Program in Computer Engineering Bo־ gazi, ci University 2011.

11. M. Durairaj, V. Ranjani. Data Mining Applications In Healthcare Sector: A Study. International journal of scientific \& technology research volume 2, issue 10, October 2013. 29-35.

12. Bhattacharya S, Maheshwari A, Mollison J (2013) Factors Associated with Failed Treatment: an Analysis of 121,744 Women Embarking on Their First IVF Cycles. PLoS ONE 8(12): e82249. doi:10.1371/journal.pone.0082249

13. Valerie L. Baker, M.D.,a Clarence E. Jones, Ph.D.,b Barbara Cometti, Ph.D.,b Fred Hoehler, Ph.D.,c Bruno Salle, M.D., Ph.D., D.Sc.,d Janos Urbancsek, M.D.,e and Michael R. Soules, M.D.f Factors affecting success rates in two concurrentclinical IVF trials: an examination of potentialexplanations for the difference in pregnancy ratesbetween the United States and Europe. Fertility and SterilityVol 94, No. 4, September 2010. doi:10.1016/j.fertnstert.2009.07.1673

14. Veleva, Zdravka, Factors affecting the outcome of IVF/ICSI Academic Dissertation to be presented, with the assent of the Faculty of Medicine of the University of Oulu, for public defence in Auditorium 4 of Oulu University Hospital, on September 26th, 2008, at 12 noon ISBN 978-951-42-8883-8 (PDF). 


\section{AUTHORS PROFILE}

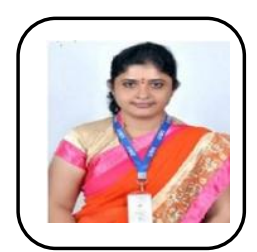

Mrs. Gowramma G.S is an Associate Professor in the Department of Information Science \& Engineering, Don Bosco Institute of Technology, Bengaluru, Karnataka, India. She has done her B.E., M.Tech. in Computer Science \& Engineering She has more than 17 years of Academic teaching both in UG \& PG, 5 years Industry \& 4 years research experience. She has published 4 papers in International Journals, 8 in International and National conferences. She is a knowledgeable professor in the field of DBMS, Data mining \& Data warehousing, Machine learning. She has organized more than 20 invited talks, has coordinated \& conducted 2 National conferences, 10 FDP's, 5 workshops at DBIT.6 NPTEL FDP Certification. Given Presentation to NBA Committee. Worked for Both NAAC \& NBA. She is also Life time member in ISTE, CSI.

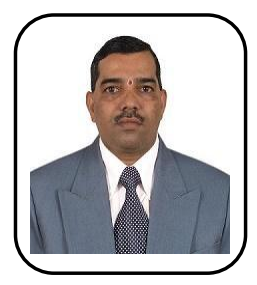

Dr. Shantharam Nayak is a Professor in the Department of Information Science \& Engineering, R. V. College of Engineering, Bengaluru, and Karnataka, India. He has done his B.E., M.S. and $\mathrm{PhD}$ in Computer Science \& Engineering. He has more than 25 years of Academic teaching \& research experience both in UG \& PG. He has guided and is guiding $\mathrm{PhD}$ students. $\mathrm{He}$ has published 38 papers in International Journals, 15 in International and National conferences. He is a knowledgeable professor in the field of Software Engineering. He is associated with CSI since 1992. He has organized more than 90 invited talks, has coordinated \& conducted 2 International \& 6 National conferences, 11 FDP's, 18 workshops at RVCE. He was responsible for starting CSI student branch in RVCE and bagged "CSI Best student branch Region 5" award consecutively Eight times since 2005-06. He is honored with Fellow of IE; Significant contribution, Longest Continuous SBC \& Patron Award from Computer Society of India.

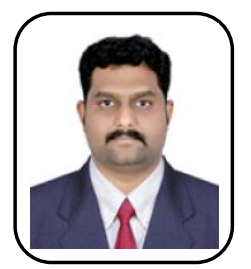

Dr. Nagaraj G Cholli, B.E in Computer Science \& Engineering in Visvesvaraya Technological University Belagavi, Karnataka, India. M.TECH in Computer Science \& Engineering in IIT-Roorkee India, Ph.D. in Visvesvaraya Technological University, Belagavi, India., completed in the year 2016 in the field of "Software Aging and Rejuvenation". He is presently working as Associate Professor at Department of Information Science and Engineering, R.V College of Engineering, Bengaluru, India. Karnataka with 13+ years of Research, Industry \& Teaching experience in India \& Abroad. Research Guidance: Total no of PG guided: 26 and Total no of Ph.D. guiding: 06. He is working on consulting and funded Projects approved by government of Karnataka and India. He has published more than 30 Research papers in various National \& Inter National Conferences/Journals and Filled 6 patent. $\mathrm{He}$ is also Life time member in ISTE, CSI, Sciei, IAENG, IRED professional societies. 